\title{
Building an aquarium in Koya districts and surroundings as a project in the tourism sector
}

\author{
J. R. Hama \\ Chemistry Department, Faculty of Science and Health, Koya University, \\ Kurdistan, Iraq
}

\begin{abstract}
An outline for any project is a crucial part because it is improves the quality of the project, beside all of the consequences that will be expected. Kurdistan starts to develop and grow in all aspects; tourism, industry, education, etc, as government and relative ministries are concerned. An aquarium is a place of refreshment to keep and exhibit animals and plants that live in water. An aquarium can be used for different purposes; for example, for education, research, investment and environmental protection. In Kurdistan, there is no aquarium; it can be built by the government and it can be proposed to the private sector, since it is the missing part of the tourism industry. Koya city is one of the locations that are suitable for an aquarium as it is easy to access by civilians from Sulaimani, Hawler and Kirkruk and it is beside Dukan's lake. The project needs a plan and efforts to be made.
\end{abstract}

Keywords: Koya city, aquarium, public aquarium, tourism sector.

\section{General background}

\subsection{Tourism planning}

Planning is about setting and meeting objectives. It is concerned with anticipating and regulating change in a system to promote orderly development so as to increase the social, economic and environmental benefits of the development process [1]. To do this, planning becomes an ordered sequence of operations, designed to lead to the achievement of either a single goal or to a balance between several goals. Communities are very often threatened with unwanted developments and face problems from unplanned or carelessly planned 
tourism expansion. In order to overcome these multi-faced problems, comprehensive tourism planning is needed to maximise the benefits and minimise the costs or disadvantages of tourism development through the involvement of the local community, who have to live with the tourists and the costs and benefits they bring [2]. In an attempt to eliminate environmental costs, many countries have included in their legislation environmental impact assessment for all projects, including tourism. The aim is to predict the environmental consequences of a proposed development activity [3].

There are many projects that government can invest in to develop tourism, as long as the project is strategic and unique it will attract tourism more from local and from close countries. As the other projects already got to slope. The project should be chosen based on suitability because the provider should invest huge money to get the project finished $[1,4]$. There are numbers of malls, zoos, public parks and rest places etc.; however there is no aquarium in Kurdistan. Even a aquarium is a new kind of refreshment place for the Middle East.

\subsection{Aquarium}

An aquarium is a vivarium consisting of at least one transparent side in which water dwelling plants or animals are kept. Aquaria is used to keep all living organism that live in water. Aquarium, typically constructed of glass or high strength acrylic plastic. Specialized equipment maintains appropriate water quality and other characteristics suitable for the aquarium's residents [5].

A public aquarium is the aquatic counterpart of a zoo, which houses living aquatic animal and plant specimens for public viewing. Most public aquariums feature tanks larger than those kept by home aquarists, as well as smaller tanks. The largest tanks in aquarium hold millions of gallons of water and can house large species, including sharks or beluga whales. Aquatic and semi aquatic animals, including otters and penguins, may also be kept by public aquaria. Public aquaria may also be included in larger establishments such as a marine mammal park or a marine park [6].

Modern aquarium tanks can hold millions of litres of water and can house large species, including dolphins, sharks or beluga whales. Some establishments, such as the Oregon Coast Aquarium or the Monterey Bay Aquarium, have aquatic aviaries. Modern aquariums also include land animals and plants that spend time in or near the water $[3,7]$.

\subsection{Materials of an aquarium}

Most aquaria consist of glass panes bonded together by $100 \%$ silicone sealant, with plastic frames attached to the upper and lower edges for decoration. The glass aquarium is standard for sizes up to about 1,000 litres and more [8]. An aquarium can range from a small glass bowl containing less than 1 litre of water to immense public aquaria that house entire ecosystems such as kelp forests [7]. The typical hobbyist aquarium includes a filtration system, an artificial lighting system, and a heater or chillers depending on the aquarium's inhabitants. Many 
aquaria incorporate a hood, containing the lights, to decrease evaporation and prevent fish from leaving the aquarium (and anything else from entering the aquarium) [8, 9]. An aquarium must be maintained regularly to ensure that the animals are kept healthy. Daily maintenance consists of checking the fish for signs of stress and disease [10-12]. Water movement can also be important in simulating a natural ecosystem. Water movement can be controlled via aeration from air pumps, power heads, and careful design of internal water flow (such as location of filtration system points of inflow and outflow) [8, 12].

\subsection{Uses of an aquarium}

There are many purposes that an aquarium can be used for:

- For marketing purposes, many aquariums promote special exhibits, in addition to their permanent collections. Some have aquatic versions of a petting zoo. For instance, The Monterey Bay Aquarium has a shallow tank filled with common types of rays which visitors are encouraged to touch. Public aquariums designed for exhibition of large species or environments can be dramatically larger than any home aquarium [3].

- Most public aquariums are located close to the ocean, for a steady supply of natural seawater. For example, an inland pioneer was Chicago's Shedd Aquarium that received seawater shipped by rail in special tank cars [3].

- During holidays and summers, aquariums often have special displays as well as special discounts on admission prices. Some aquariums even offering visitors the opportunity to scuba dive in their displays.

- Public aquariums are wonderful learning experiences especially for children. Many facilities offer educational materials and programs. School groups can usually get special rates, and are provided with chaperones to conduct a customized tour for the group. Most of the larger aquariums offer both offsite and onsite educational programs [2].

- Don't forget that every aquarium or zoo has a curator (often several). Curators are very dedicated people who are passionate about their trade. If you contact the curator of the aquarium you want to visit, they will be delighted to work with your school group.

- Some aquariums and zoos even offer the option to use their facilities to hold special events outside of normal business.

- Public aquariums are often affiliated with oceanographic research institutions or conduct their own research programs, and sometimes specialize in species and ecosystems that can be found in local waters. For example, the Vancouver Aquarium in Vancouver, BC is a major centre for marine research, conservation, and marine animal rehabilitation, particularly for the rich ecosystem of the Pacific Northwest [1]. 


\subsection{Current examples}

Here, we will show two examples of aquarium around the world to familiarise ourselves with the idea of an aquarium in Kurdistan Region.

The Turkuazoo aquarium was opened in 2009. Turkuazoo is Turkey's first giant aquarium featuring a rainforest, flooded forest and tropical seas zones. The aquarium is located inside the Forum Istanbul Shopping Mall and contains an 80 meter long underwater tunnel (as shown in Figure 1). Turkuazoo holds about 10,000 sea creatures including tiger sharks, giant stingrays and piranhas in 29 different exhibits where the largest holds 5 million litres (1.32 million gallons) of water [3].

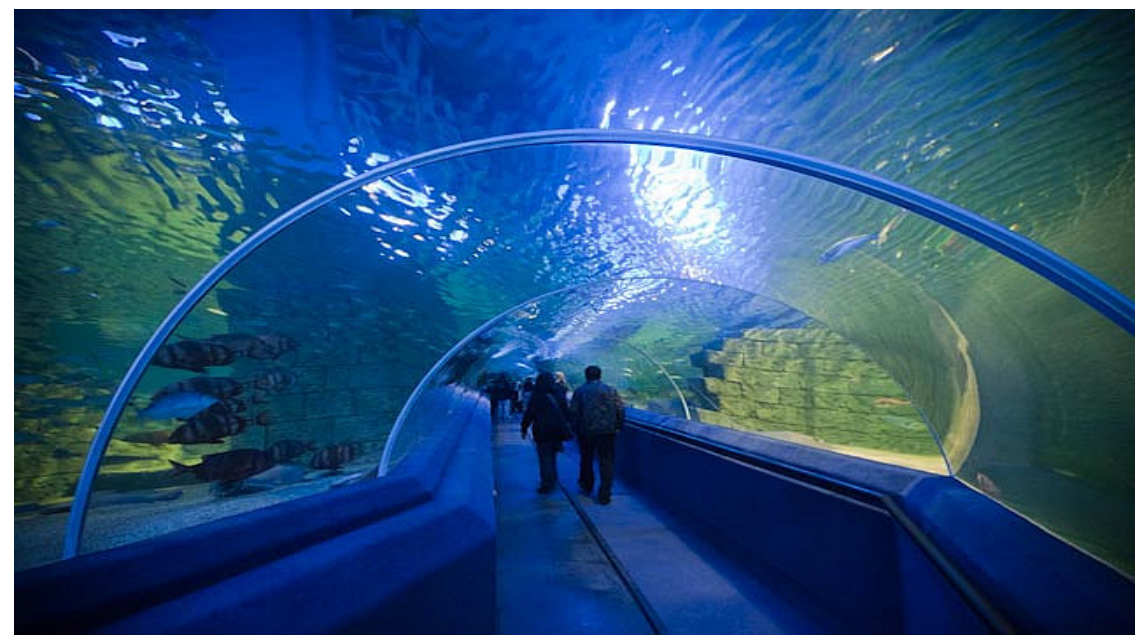

Figure 1: $\quad$ The main underwater tunnel in Turkuazoo Aquarium.

The Dubai Mall (Figure 2), one the world's largest shopping malls in the world, is part of the 20-billion-dollar Burj Dubai complex in Dubai. The centrepiece of the mall is the gigantic aquarium tank, with the capacity to hold 10 million litres (2.64 million gallons) of water. The aquarium has more than 33,000 living animals including over 400 sharks and rays combined. It officially earned the Guinness World Record for the world's “Largest Acrylic Panel” [3].

\section{An aquarium in Koya city and surroundings}

Thus, the idea of planning of aquarium is possible to be applied in Kurdistan, as it has already been done in Turkey and Dubai as the closet places to Kurdistan. There are natural water in Kurdistan such as Dukan's lake and Sirwan (Big)'s lake, Mosul Dam Lake and Alwand river, they make the project of an aquarium feasible. 


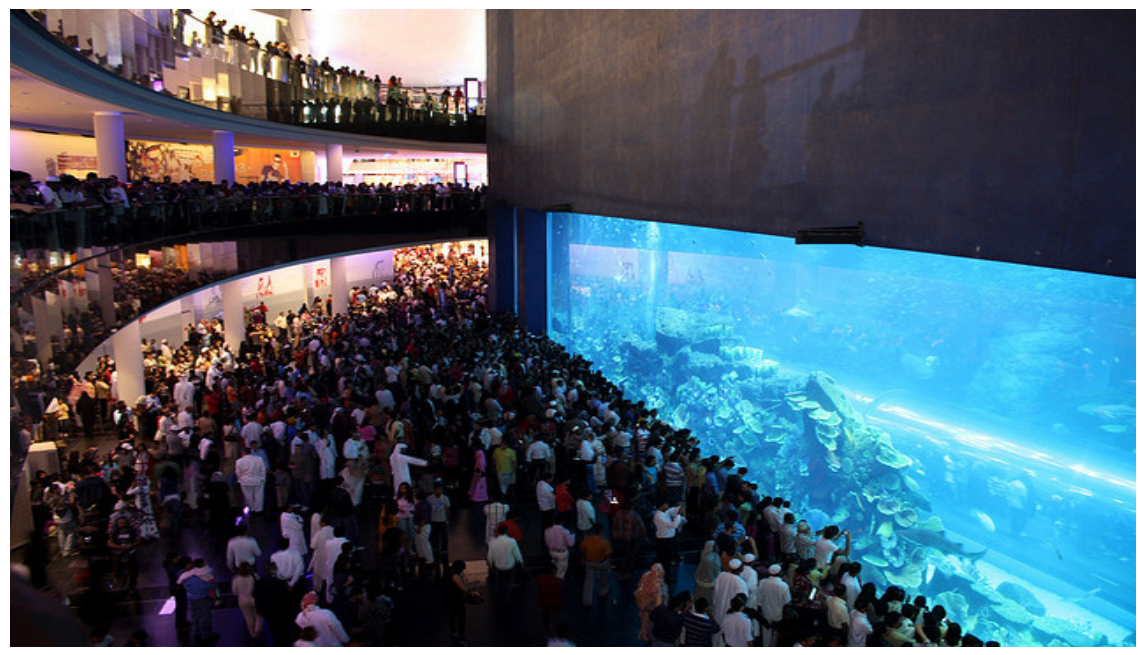

Figure 2: The main screen in Dubai Mall. You can see how the audience is surprised!! This is what an aquarium does!

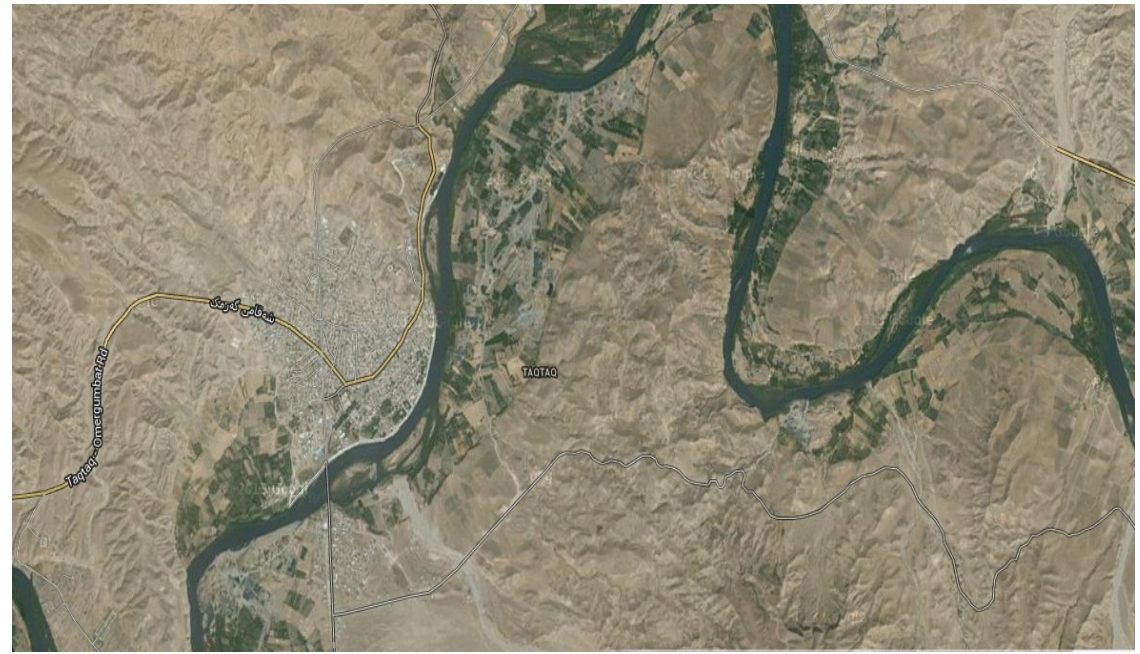

Figure 3: Satellite image of Taq taq sub-district in Koya city, from Google/map.

In Koya district, Dukan's lake passes across Taq taq sub-district, which is nearly $30 \mathrm{~km}$ far from Koya city. In Koya city and the surrounding in Taq taq particularly the water used for agriculture purposes. If the water used for this project that quantity and quality of the water will not changed. Along the coast of Taq taq is suitable for an aquarium because the lake will provide sufficient amount of water and it is easy location to get, as shown in Figure 3. 
The location of Koya city is suitable for an aquarium and for other tourism projects because it is located between the three governorates; Sulaimani, Hawler and Kirkruk. Beside that Koya is close to many districts, such as Rania, Qalazde and Dukan. This will help to tourists and visitors in those three governorates to travel to Koya city and see the aquarium.

If establishing an aquarium is not possible in Taq taq, it can be done inside Koya city. There is Hamamok spring in the north of Koya, which provides drinking water for the city. With help of a project the amount of water can be increased to provide water for drinking and aquarium uses. Building an aquarium in this location would be potential project because the spring is a part of Koya city and easy to access. However there are other efforts that have to made, for example, providing enough space for an aquarium building and make the access better for the area especially of roads and transportation.

There are many advantages of an aquarium in Koya. The aquarium could be a great source for Koya University to conduct their scientific researches in the wild life in an aquarium, either on animals and plants. Because one of the main uses of an aquarium is that it can be used for research purposes as studies at Vancouver Aquarium in Vancouver.

An aquarium will increase the opportunity of employing new local people from Koya. Also helps to improve experiences of the employees.

Aquarium helps to protect the environment of the city in particular and Kurdistan in general. It can be used to exhibit the animals and plants the live in the city and Kurdistan. Also to show other animals and plants are very rare or not exist in Kurdistan. Another aspect to conserve those species of animals and plants that under threaten by environmental changes or human. As the number and kind of many species dropped considerably in the past.

\section{Conclusion}

Planning for any project is to improve the quality of it. Planning for building an aquarium in Kurdistan will help the tourism sector to grow. An aquarium offers various services, for instance for education to show the world of animals and plants that live in water, for research, and for the tourism industry. Building an aquarium in Koya city will help to improve tourism in Koya city in particular and Kurdistan in general. The project will turn the tourism sector to a new level as it will be experienced for the first time. There are other advantages of an aquarium for the city, such as making the city an attraction place, increasing the opportunity for employees and environmental conservation.

\section{References}

[1] Andriots, K., A Framework for the Tourism Planning Process Sustainability, profitability and Successful Tourism (1 ${ }^{\text {st }}$ Ed.), Kanishka Publishers, New Delhi, 2007 (ISBN: 81-7391-919-4). 
[2] Lange, J., and Tai, M., A Visit to the Zoos and Aquariums in Japan II. Der Zoologische Garten N.F, 2013. (In press http://dx.doi.org/10.1016 /j.zoolgart.2013.07.001)

[3] Touropia, (2010), http://www.touropia.com/quariums (accessed on 7/9/ 2013).

[4] Fazio, R. and Jannelli, A., Mathematical and numerical modeling for a bio-chemical aquarium. Applied Mathematics and Computation, 174, pp. 1370-1383, 2006.

[5] Bernoth, E. M. and Crane, M. J., Viral Diseases of Aquarium Fish. Seminars in Avian and Exotic Pet Medicine, 4, pp. 103-110, 1995.

[6] Tlusty, M., The benefits and risks of aquacultural production for the aquarium trade. Aquaculture, 205, pp. 203-219, 2002.

[7] Koldewey, H. J., and Smith, K. M., A global review of seahorse aquaculture. Aquaculture, 302, pp. 131-152, 2010.

[8] Landman, M. J. and Heuvel, M. R., An improved system for the control of dissolved oxygen in freshwater aquaria. Water Research, 37, pp. 43374342, 2003.

[9] Verheijen, F. J. and De Groot, S. J., Diurnal Activity Pattern OF Plaice and Flounder (Pleuronectidae) in Aquaria. Netherlands Journal of Sea Research, 3, pp. 383-390, 1967.

[10] New, M. B., Scholl, J. P., Mccarty, J. C. and Bennett, J. P., A Recirculation System for Experimental Aquaria. Aquaculture, 3, pp. 95103, 1974.

[11] Mali, B. and Lovell, R.T., Diet Preparation for Aquarius Fishes. Aquaculture, 12, pp. 53-62, 1977.

[12] Bjordal, Ch. G., Nilsson, T. and Petterson, R., Preservation, storage and display of waterlogged wood and wrecks in an aquarium: "Project Aquarius’’. Journal of Archaeological Science, 34, pp. 1169-1177, 2007. 